\title{
Phenotypical Characterization of a Mutant deal With Developmental Defect in Female Inflorescence and Mutantion Impact on Yield in Maize
}

\author{
Fei Zheng ${ }^{1}$, Meijing Zhang ${ }^{1}$, Yiwen Zhen ${ }^{1,3}$, Jianhua Yuan ${ }^{1}$, Wenming Zhao ${ }^{1}$, Lingjie Kong ${ }^{1}$, Ruixiang Liu ${ }^{1}$, \\ Yakun Cui ${ }^{1}$, Jing Chen ${ }^{1}$, Yanping Chen ${ }^{1} \&$ Qingchang Meng ${ }^{1,2}$ \\ ${ }^{1}$ Institute of Food Crops, Jiangsu Academy of Agricultural Sciences, Nanjing, Jiangsu, China \\ ${ }^{2}$ Institute of Life Sciences, Jiangsu University, Zhenjiang, Jiangsu, China \\ ${ }^{3}$ College of Agriculture, Nanjing Agricultural University, Nanjing, Jiangsu, China \\ Correspondence: Qingchang Meng, Institute of Food Crops, Jiangsu Academy of Agricultural Sciences, 50 \\ Zhongling Street, Xuanwu District, Nanjing 210014, Jiangsu, China. Tel: 86-25-8439-0308. E-mail: \\ qcmeng@jaas.ac.cn \\ Yanping Chen, Institute of Food Crops, Jiangsu Academy of Agricultural Sciences, 50 Zhongling Street, \\ Xuanwu District, Nanjing 210014, Jiangsu, China. Tel: 86-25-8439-0308. E-mail: chenyp@jaas.ac.cn \\ Received: October 7, $2021 \quad$ Accepted: December 10, $2021 \quad$ Online Published: January 15, 2022 \\ doi:10.5539/jas.v14n2p1 URL: https://doi.org/10.5539/jas.v14n2p1
}

The research is financed in part by grants from National Science and Technology Support Project of China (2016YFD0101205), the Natural Science Foundation of Jiangsu Province, China (BK20160586), the Special Funds of the Modern Agricultural Industry Technology System of China (CARS-02), as well as Six Talent Peaks Project of Jiangsu Province, China (NY-020).

\begin{abstract}
The establishment of female inflorescence morphology is of great significance to the formation of final maize yield. defective earl (deal) is a novel maize mutant with developmental defect of female inflorescence caused by natural variation. Morphological analysis revealed that the mutant deal was characterized as a "scar-like" crack on the adaxial side of the top of the ear, accounting for $28.6-100.0 \%$ of the ear length, with an average of $32.4 \%$. The results of scanning electron microscope showed that there was collapse in the formation of paired spikelet primordium at the base of the axillary meristem. Most of investigated botanical and agronomical traits of deal were lower than those of wild type, except for ear length and hundred grain weight. The grain yield per ear of mutant deal was $35.93 \%$ lower than that of wild type, and the width of mutation crack contributed the most to the yield loss per ear. The identification of the mutant deal and the characteristically phenotypic analysis provide a theoretical basis for the study of the molecular regulation mechanism of ear development and the application of high-yield breeding in maize.
\end{abstract}

Keywords: maize (Zea mays L.), inflorescence development, mutant, yield, spikelet pair meristems

\section{Introduction}

Maize is one of the most agriculturally important crops, due to the supply of food and industrial raw materials in the world. Moreover it has been severing as one of the model organisms for plant genetics research (Bennetzen et al., 2001; Schnable et al., 2009). Maize inflorescence is an important female reproductive organ, and it is well fitted for studying the mechanism of floral transformation, inflorescence morphogenesis, floral organ development and as well as seed development. Maize ear, the mature output of female inflorescence, is the main agricultural harvest organ, which directly determines the final yield in maize production.

Maize ears, also known as female ears, belong to the fleshy inflorescence. The cobs are hypertrophy and covered with very compact and dense rachis nodes. Each node has two sessile spikelets, arranged in pairs in rows. The female inflorescence develops from leaf buds in the leaf axils and is attached to the top of the panicle stalk. The development of maize female inflorescence experience two stages: sex determination and inflorescence formation (Cheng et al., 1983; Li et al., 2018; Kitagawa \& Jackson, 2019; Somssich et al., 2016; Vollbrecht \& 
Schmidt, 2009). In the vegetative growth stage, the shoot apical meristem (SAM) initiates leaf development, and there is an axillary meristem (AM) at each leaf axil. After a certain growth stage, maize is induced by light, temperature, nutrition and other factors to induce reproductive conversion. The apical meristem not only maintains itself, but also differentiates into axillary meristem. After a period of dormancy, the primordia of axillary meristem expanded and elongated to form female inflorescence meristem (IM). Three types of axillary meristems were produced successively by IM which finally formed maize spikelet pair meristems (SPM), spikelet meristem (SM) and floret meristem (FM) (Tanaka et al., 2013; Vollbrecht \& Schmidt, 2009). In this process, the transformation from IM to SPM determines the final row number of corn ear.

In this series of transformation, multiple gene family members and plant hormones are involved in the coordinated regulation of meristem activities. In recent years, with the continuous advancement of molecular genetic methods, the regulatory network of spikelet development has been initially identified (Vollbrecht and Schmidt, 2009). However, the mechanism of how some key genes finely regulate maize ear development is still unclear.

In this study, a maize ear development defect mutant was identified. The mutation affected the number of rows at the top of ear, and ultimately affected the formation of final yield. The discovery of this mutant may lay a foundation for further elucidating the mechanism of ear morphogenesis in maize.

\section{Method}

\subsection{Plant Materials and Growth Conditions}

One of progenies of a mating cross (LG14/Su95-1) was found to be defect in ear morphology. The line with defect ears was selfing maintained to nearly genetic purity. Finally the mutant line, named L19G108, and its wild type sister line (CK) were used in this study. B73, Zheng58 and Mo17 were used to construct segregation populations for genetic analysis. The most significant feature of L19G108 is that there is a "scar" like crack on the adaxial side of the top of the ear, and the number of rows in the top of the ear decreases greatly. The mutantion gene conferred in L19G108 was tentatively named defective earl (deal).

\subsection{Investigation of Agronomic and Yield-Related Traits}

The mutant dealand CK were sown in Hainan breeding station (Sanya, E109.00, N18.36) in winter of 2018, and in Luhe experimental base of Jiangsu Academy of Agricultural Sciences (Nanjing, E118.62, N32.48) in spring of 2019. More than 30 plants were randomly selected and recorded from the mutant and CK for measurement of agriculturally important traits, such as plant height, ear height, leaf width, leaf length, leaf number, length of main tassel branch and number of tassel branch. The recorded plants were open pollinated in the field for further investigation of yield-related traits after harvest. The ear weight, grain weight, cob weight, total number of grains per ear and hundred grain weight were measured. Ten grains were randomly selected from the middle of the ear to measure the grain length, width and depth, and calculate the average value of each character.

\subsection{Mutation Phenotype Observation}

Vernier caliper was used to measure the length and maximum width of defect mutation site in maize ear, and the normal degree of every mutant ear was calculated as Equation 1.

$$
\text { Normality }(\%)=100-(\text { Mutant crack length/Ear length }) \times 100
$$

\subsection{Scanning Electron Microscope (SEM) Analysis}

The mutants and wild-type plants of about $2 \mathrm{~cm}$ in length at V7 stage were selected and fixed with $2 \%-3 \%$ glutaraldehyde for 2 hours, then dehydrated in ethanol gradient and stored in $100 \%$ acetone. The samples were processed by critical point drying and gold spraying, and then imaged by scanning electron microscopy (Zeiss EVO-LS10, Germany). The experimental material processing and imaging were completed in the Central Laboratory of Jiangsu Academy of Agricultural Sciences (http://lab.jaas.ac.cn).

\subsection{Statistical Tests}

The $P$ value based on a two-tailed $t$-test was used to compare the difference of phenotypic mean between wild type and mutant in R (R Core Team 2019; http://www.R-project.org/). Stepwise regression analysis was used to analyze the effect of traits on yield per ear.

\section{Results}

\subsection{Discovery of Ear Development Defect Mutant}

We found a single ear with developmental defect among 5 harvested maize ears in $\mathrm{F}_{5}$ generation derived from a mating cross. The defective trait resembled as tip-barrenness resulted from unfertilized florets and/or premature 
cessation of fertilized florets during the grain filling stage, especially at the tip of the ear cob due to environmental stress. However, there were no any pedicels on the site of defective cob. After at least another 5 generations of repeat selfing, the inbred line L19G108 with desired mutation was obtained, as well as the control line L19G056 (Figure 1A). For short, the mutant was named defective earl (deal).

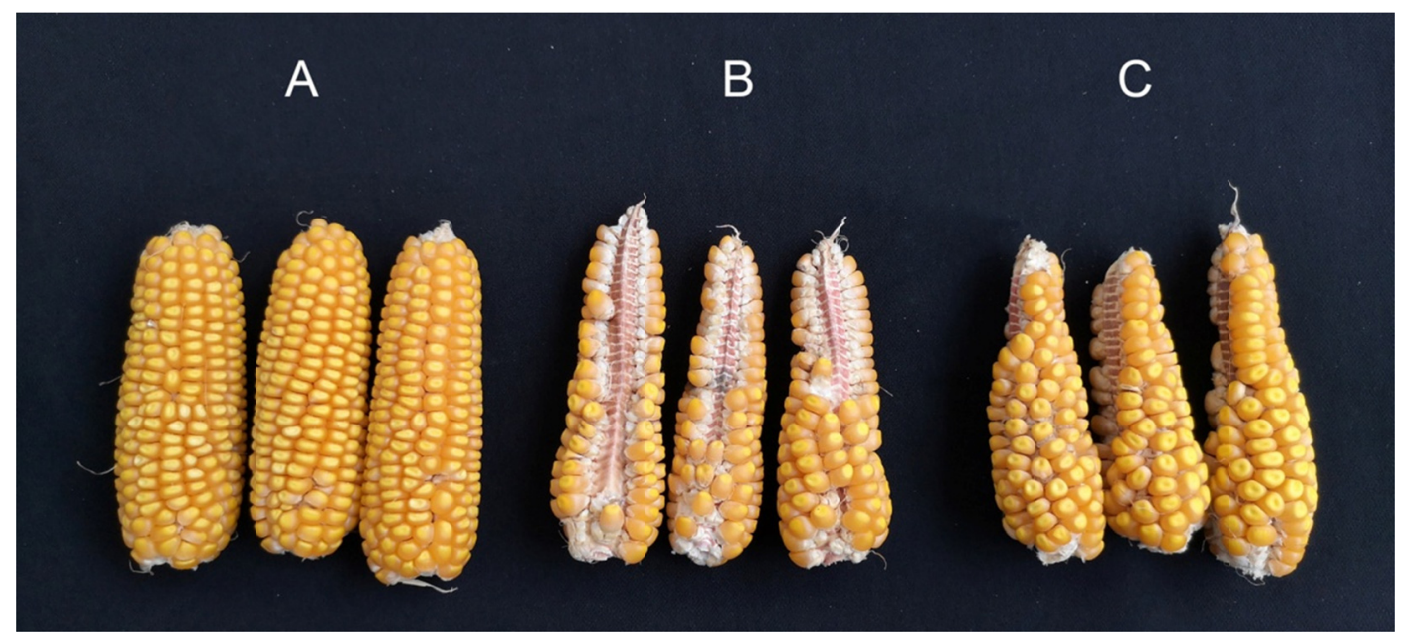

Figure 1. Ears of wild type line and mutant line deal. A: wild type line, B: mutant line from the adaxial side view; C: mutant line from the lateral view

\subsection{Characteristics of the Mutant}

There is a crack on the mature ear of mutant deal, from which the cob can be seen, and no florets are attached to the fissure part (Figures 1B and 1C). The average length of the fissure is $7.42 \mathrm{~cm}$ with a range of $3.0-12.2 \mathrm{~cm}$ in two seasons. The length of the fissure accounts for $28.6-100.0 \%$ of the ear length, with an average of $32.4 \%$.

The ear rows of wild type line are regular in pairs, ranged from 12 to 14, with an average of 13.2 rows. In comparison, the ear row mutation side of the mutant was very irregular or disordered, and the number of ear rows was uncountable. Ear rows increased from the top to the base, and most ears can recover to the wild type. We further found that the mutation was generally located in the adaxial surface. Notably, there are $57.7 \%$ of the lower ears showed the same mutant phenotype.

\subsection{Scanning Electron Microscope Analysis}

The immature female inflorescence of wild-type and mutant type were analyzed by SEM. As shown in Figure 2, the inflorescence meristems in both wild (Figure 2A) and mutant line (Figure 2B) begins to develop in the elongation period of female inflorescence. The surface of the growth cone of wild type female inflorescence is smooth with broad base, and the width is greater than the length. However, the surface of the mutant growth cone was smooth, and its length and width were similar. The growth cones of wild type differentiated into paired floret primordia, while the position of paired floret primordia of mutant was lower than that of wild type. In wild type inflorescence, there are SPMs in line while the female inflorescence of the mutant was obviously sunken under the primordium, and no SPM was formed in the depression, and the pairs of floret primordia on both sides were disordered. There is an inverted triangle at the base of the depression, which may be the place where the mutation occurs initially. 


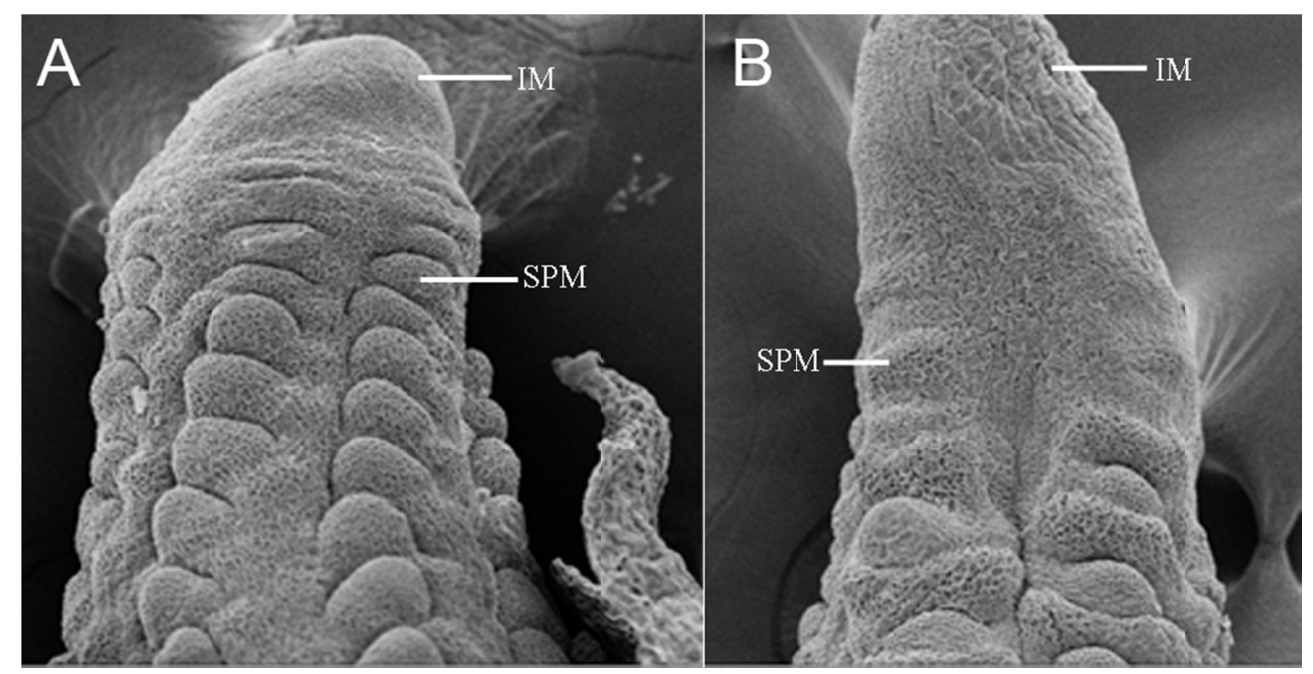

Figure 2. Scanning electron micrographs of the immature female inflorescence of wild and mutant lines. A: Wild type line; B: mutant line

\subsection{Morphological Characteristics of Mutants}

Although the mutants have the same days to anther and leaf width to wild type, there were significant or extremely significant differences between them for most morphological traits observed in this study (Table 1). For example the mutants are $36.50 \mathrm{~cm}$ shorter than wild in plant height and $23.42 \mathrm{~cm}$ shorter in ear height. Interestingly, tassel branch number of the mutants is 1.63 less than that of wild.

Table 1. Comparison of main agronomical and yield-related traits (Sanya in 2018)

\begin{tabular}{lllll}
\hline \multirow{2}{*}{ Trait } & \multicolumn{2}{c}{ Means \pm SD } & \multirow{2}{*}{$t$ value } & \multirow{2}{*}{$P(>|t|)$} \\
\cline { 2 - 4 } & Wild & Mutant & & \\
\hline Plant height $(\mathrm{cm})$ & $178.30 \pm 12.67$ & $141.80 \pm 10.48$ & 5.846 & 0.000 \\
Ear height $(\mathrm{cm})$ & $60.83 \pm 4.61$ & $37.44 \pm 5.41$ & 8.997 & 0.000 \\
Leaf width above ear $(\mathrm{cm})$ & $8.37 \pm 0.45$ & $8.20 \pm 0.78$ & 0.775 & 0.461 \\
Leaf length above ear $(\mathrm{cm})$ & $68.13 \pm 1.90$ & $59.16 \pm 2.40$ & 7.633 & 0.000 \\
tassel branch number & $9.14 \pm 0.64$ & $7.51 \pm 0.78$ & 4.992 & 0.000 \\
tassel length $(\mathrm{cm})$ & $30.29 \pm 1.36$ & $26.51 \pm 1.68$ & 4.518 & 0.003 \\
Ear weight $(\mathrm{g})$ & $69.95 \pm 7.35$ & $44.41 \pm 9.82$ & 11.493 & $<2.2 \mathrm{e}-16$ \\
Grain weight per ear $(\mathrm{g})$ & $57.61 \pm 6.16$ & $34.62 \pm 8.49$ & 12.098 & $<2.2 \mathrm{e}-16$ \\
Cob weight per ear $(\mathrm{g})$ & $12.36 \pm 1.61$ & $9.79 \pm 1.63$ & 6.101 & 0.000 \\
Ear length $(\mathrm{cm})$ & $9.67 \pm 0.92$ & $10.51 \pm 0.61$ & 4.123 & 0.000 \\
Cob diameter $(\mathrm{mm})$ & $22.38 \pm 0.98$ & $19.52 \pm 1.93$ & 7.375 & 0.000 \\
Grain number & $280.71 \pm 29.26$ & $143.66 \pm 32.24$ & 17.225 & $<2.2 \mathrm{e}-16$ \\
Hundred grain weight $(\mathrm{g})$ & $20.59 \pm 1.66$ & $24.13 \pm 2.71$ & 6.181 & 0.000 \\
\hline
\end{tabular}

\subsection{Mutation Effect on Yield Traits}

As for ear-related traits, ear weight, cob weight, grain weight, grain number and cob diameter of mutants were significantly lower than those of wild type, while ear length and hundred grain weight of mutants were significantly higher than those of wild type (Table 1). In two growth seasons the grain weight of the mutant was $30.0 \%$ and $39.9 \%$ lower than that of the wild type, respectively. On average, the grain yield of mutant was $35.93 \%$ lower than that of wild type. Moreover, grain length of mutant was smaller than that of wild type (Figure $3 \mathrm{~A}$ ), but the width and thickness of grain were higher than that of wild type (Figures 3B and 3C). 

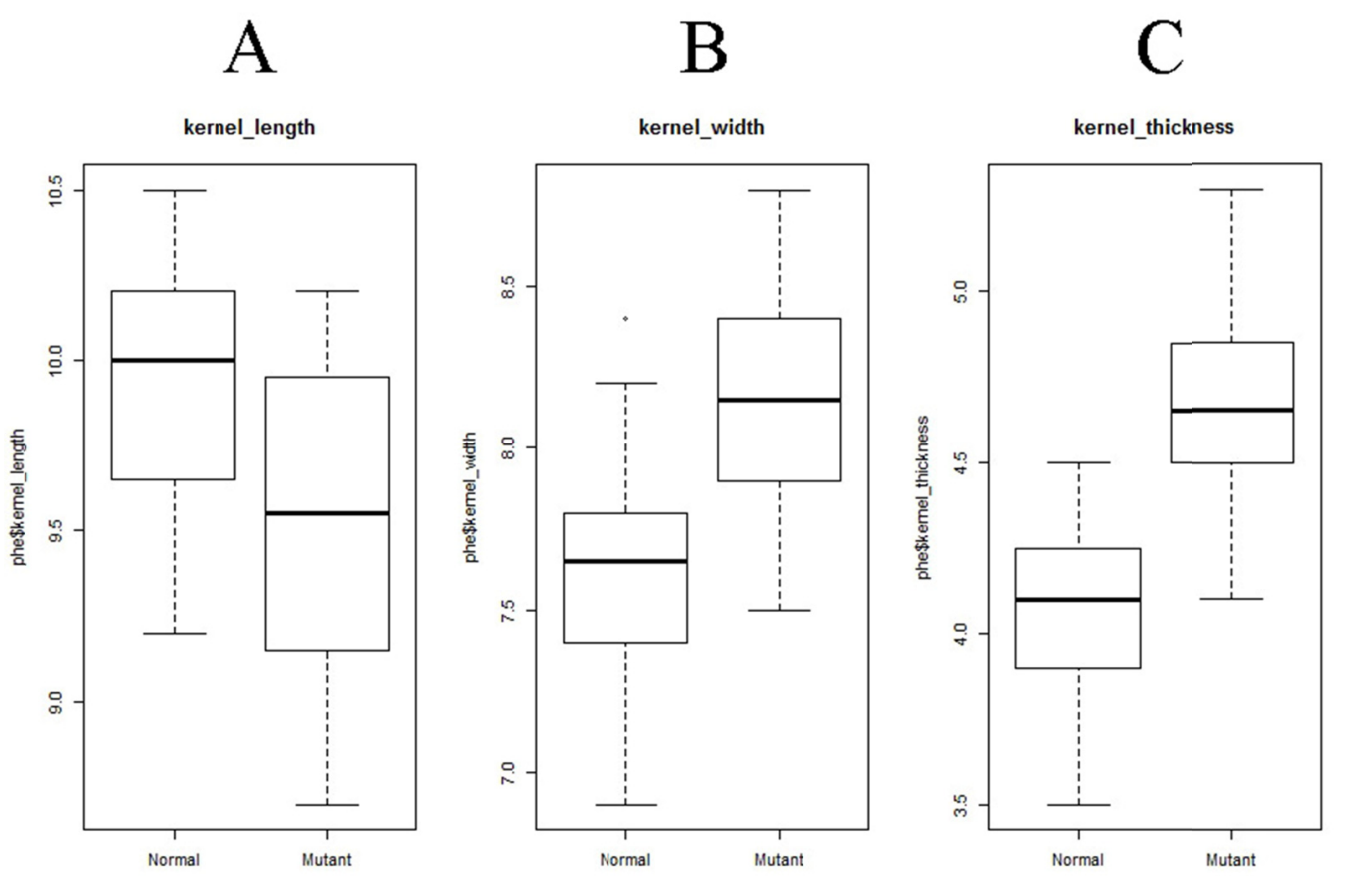

Figure 3. Comparison of grain length, width and thickness between mutant and wild type. A: Kernel_length; B:

Kernel_width; C: Kernel_thickness

In order to determine the effect of mutation on ear yield, regression analysis was carried out by ear traits. The results (Table 2) showed that the effects of the crack width, ear length and hundred grain weight of the mutant on ear grain weight were extremely significant, and the effect of the fissure length was significant. Ear rows, an important determinant of yield, is directly affected by crack width. The larger the crack width, the fewer the ear rows, and the fewer grains and the lower yield. In addition, the correlation analysis also showed that there was a very significant positive correlation between crack length and width (Pearson correlation coefficient $r=0.646, P$ $=6.605 \mathrm{e}-05)$.

Table 2. Stepwise regression analysis of traits against ear yield

\begin{tabular}{lllll}
\hline Trait & $b$ estimate & Standard error & $t$ value & $P(>|t|)$ \\
\hline Crack length $(\mathrm{cm})$ & -1.297 & 0.527 & -2.459 & 0.017 \\
Crack width $(\mathrm{cm})$ & -2.333 & 0.478 & -4.886 & 0.000 \\
Ear length $(\mathrm{cm})$ & 4.343 & 0.715 & 6.075 & 0.000 \\
Hundred grain weight $(\mathrm{g})$ & 1.011 & 0.253 & 4.000 & 0.000 \\
\hline
\end{tabular}

A path coefficient indicates the direct effect of a variable assumed to be a cause on another variable assumed to be an effect (Table 3). The path analysis of yield per panicle was made with four significant variables in regression analysis. The results showed that the variation of yield per panicle was $0.914 \%$ and the residual path coefficient was 0.292. Among them, the width of fissure plays an important role in the yield per panicle, and its direct path coefficient is -0.841 ; the influence of fissure length on single ear yield is the second, and it is mainly indirectly affected by the fissure width (the indirect path coefficient is -0.807). 
Table 3. Path analysis of four ear-related traits to yield

\begin{tabular}{|c|c|c|c|c|}
\hline Item & $\begin{array}{l}\text { Ear length } \\
\mathrm{X} 1 \rightarrow \mathrm{Y}\end{array}$ & $\begin{array}{l}\text { Hundred grain weight } \\
\mathrm{X} 2 \rightarrow \mathrm{Y}\end{array}$ & $\begin{array}{l}\text { Crack length } \\
\mathrm{X} 3 \rightarrow \mathrm{Y}\end{array}$ & $\begin{array}{l}\text { Crack width } \\
\mathrm{X} 4,4 \rightarrow\end{array}$ \\
\hline Ear length $\mathrm{X} 1,1 \rightarrow$ & $0.283^{\mathrm{a}}$ & 0.063 & -0.152 & -0.404 \\
\hline Hundred grain weight $\mathrm{X} 2,2 \rightarrow$ & 0.093 & $\underline{0.190^{\mathrm{a}}}$ & -0.196 & -0.437 \\
\hline Crack length $\mathrm{X} 3,3 \rightarrow$ & 0.136 & 0.118 & $-0.316^{\mathrm{a}}$ & -0.807 \\
\hline Crack width $\mathrm{X} 4,4 \rightarrow$ & 0.136 & 0.099 & -0.304 & $\underline{-0.841^{\mathrm{a}}}$ \\
\hline
\end{tabular}

Note. ${ }^{a}$ Direct path coefficient is underlined.

\section{Discussion}

The mutant deal was originally identified in a breeding population. The surprising defective ear once was mistakenly attributed to ear barren tip, which composed from aborted kernels and florets without fecundation at the tip of ear. Unlike ear barren tip, the mutants seem to be independent to environmental stress. Our SEM analysis showed that the mutantion is caused by the failure of SPM formation (Figure 2A), which occurs much earlier than florets formation or kernel filling in the process of female inflorescence development. Path analysis (Table 3) suggested that the earlier the mutation occurs, the longer the fracture length and the larger the fracture width of mutant ear is. The crack length reflects the start time and location of abrupt change when mutation begins. Reduced floret number is expected with partial reduction of the formation of SPM and then causes yield loss.

In maize, ear formation is a signal transduction process involving a series of genes regulated by complex height levels in inflorescence meristem (Bortiri \& Hake, 2007). The inflorescence meristem has the same stem cell properties as the stem apical meristem, which can maintain its own cell number and differentiate and proliferate cells at the same time (Doerner, 2001). Maintaining the dynamic balance of stem cell system requires WUS/CLV3 feedback signal regulation network (Schoof et al., 2000; Somssich et al., 2016) and WUS/AG feedback inhibition loop (Lenhard et al., 2002; Sablowski, 2007). Once the balance ring is destroyed by genetic factors or environmental factors, abnormal changes in plant morphology will occur. Our results showed that the cells under the tunica of the mutants in this study were sunken in the early stage of the development of the panicle, which may be due to the change in the expression of a gene involved in the signal regulation pathway, which destroyed the balance of stem cells and caused the development defect of the spikelet. It is speculated that the change of activity of meristem at the tip of female inflorescence may result in the lengthening of ear. Heavier grain weight in the mutant may be due to the influence of mutation on row arrangement, decrease of spikelet density and weak spatial competition among grains.

In addition to the differences of ear, the deal mutants resemble a miniature wild type in plant architecture as shown in Table 1. There are three possible assumptions for the mutation causal gene: it might affect the development of maize plants throughout the growth period; it acts in the upstream of affected traits; it is a pleiotropic gene. Further genetic analysis and mapping for the deal mutantion needs be conducted.

Previous studies have shown that genes related to inflorescence meristem are involved in auxin biosynthesis (Gallavotti et al., 2008a; Phillips et al., 2011), transportation (McSteen et al., 2007; Gallavotti et al., 2008b) and signal transduction (Skirpan et al., 2008) to regulated the morphological changes of maize inflorescence. SPII encodes a Yucca like protein gene unique to monocotyledons, which mainly acts on auxin biosynthesis. SPII mutant significantly reduces the number of grains per spike (Gallavotti et al., 2008a). The $v t 2$ gene encodes tryptophan aminotransferase, which is related to auxin synthesis. In addition to reducing the number of rows per ear, the $v t 2$ mutant also has a bald ear. In addition, $v t 2$ mutant have severe developmental defects in both vegetative and reproductive growth (Phillips et al., 2011). The pinoid gene product of Arabidopsis thaliana is serine/threonine protein kinase, which may regulate auxin transport (Benjamin et al., 2001). In maize, bif2 is homologous to pinoid lineage, and the bif2 mutant does not produce any spikes (McSteen \& Hake, 2001; Mcsteen et al., 2007); BIF1 and bif 2 are very similar and also participated in the regulation of auxin transport. The BIF1 mutant does not produce spikes or produce spikes, and the number of grains decreases and grains are disorderly arranged (Barazesh and McSteen 2008; Galli et al., 2015). On the one hand, these mutants showed the characteristics of reduced rows per panicle and dwarfed plants. The surface types of the mutants in this study were similar to those of the mutants, suggesting that auxin plays an important role in the formation of ear morphology, especially in the differentiation of primordia of paired florets. On the other hand, the mutants in this study have special phenotypic characteristics. For example, the mutation occurred on the adaxial side of the ear, 
which was obviously dorsal ventral, which may be related to the polar auxin transport (Shi et al., 2017). The ear length of the mutant indicated that the activity of inflorescence meristem was positively regulated. Therefore, the mutants found in this study may be a new class of regulatory genes involved in ear morphogenesis in maize.

\section{Acknowledgements}

We would like to thank lab.jaas.ac.cn for providing the SEM analysis platform. This work was financially supported in part by grants from National Science and Technology Support Project of China (2016YFD0101205), the Natural Science Foundation of Jiangsu Province, China (BK20160586), the Special Funds of the Modern Agricultural Industry Technology System of China (CARS-02), as well as Six Talent Peaks Project of Jiangsu Province, China (NY-020).

\section{References}

Barazesh, S., \& McSteen, P. (2008). Barren inflorescencel functions in organogenesis during vegetative and inflorescence development in maize. Genetics, 179, 389-401.

Bennetzen, J. L., Chandler, V. L., \& Schnable, P. (2001). National Science Foundation-Sponsored Workshop Report. Maize Genome Sequencing Project. Plant Physiology, 127, 1572-1578.

Bortiri, E., \& Hake, S. (2007). Flowering and determinacy in maize. Journal of Experimental Botany, 58, 909-916.

Cheng, P., Greyson, R., \& Walden, D. (1983) Organ initiation and the development of unisexual flowers in the tassel and ear of Zea mays. Am J Bot, 70, 450-462.

Doerner, P. (2001). Plant meristems: A ménage à trois to end it all. Current Biology, 11, R785-R787.

Gallavotti, A., Barazesh, S., Malcomber, S., Hall, D., Jackson, D., Schmidt, R. J., \& McSteen, P. (2008a). sparse inflorescencel encodes a monocot-specific YUCCA-like gene required for vegetative and reproductive development in maize. Proceedings of the National Academy of Sciences of the United States of America, $105,15196-15201$.

Gallavotti, A., Yang, Y., Schmidt, R. J., \& Jackson, D. (2008b). The Relationship between auxin transport and maize branching. Plant Physiology, 147, 1913-1923.

Galli, M., Liu, Q., Moss, B. L., Malcomber, S., Li, W., Gaines, C., ... Gallavotti, A. (2015). Auxin signaling modules regulate maize inflorescence architecture. Proceedings of the National Academy of Sciences of the United States of America, 112, 13372-13377.

Kitagawa, M., \& Jackson, D. (2019). Control of meristem size. Annu Rev Plant Biol, 70, 269-291.

Lenhard, M., Jürgens, G., \& Laux, T. (2002). The WUSCHEL and SHOOTMERISTEMLESS genes fulfil complementary roles in Arabidopsis shoot meristem regulation. Development, 129, 3195-3206.

Li, M., Zhong, W., Yang, F., \& Zhang, Z. (2018) Genetic and molecular mechanisms of quantitative trait loci controlling maize inflorescence architecture. Plant Cell Physiol, 59, 448-457.

McSteen, P., \& Hake, S. (2001). barren inflorescence2 regulates axillary meristem development in the maize inflorescence. Development, 128, 2881-2891.

McSteen, P., Malcomber, S., Skirpan, A., Lunde, C., Wu, X., Kellogg, E., \& Hake, S. (2007). barren inflorescence2 Encodes a co-ortholog of the PINOID serine/threonine kinase and is required for organogenesis during inflorescence and vegetative development in maize. Plant Physiology, 144, 1000-1011.

Phillips, K. A., Skirpan, A. L., Liu, X., Christensen, A., Slewinski, T. L., Hudson, C., ... McSteen, P. (2011). vanishing tassel2 encodes a grass-specific tryptophan aminotransferase required for vegetative and reproductive development in maize. The Plant Cell, 23, 550-566.

Sablowski, R. (2007). Flowering and determinacy in Arabidopsis. Journal of Experimental Botany, 58, 899-907.

Schnable, P. S., Ware, D., Fulton, R. S., Stein, J. C., Wei, F., Pasternak, S., .. Graves, T. A. (2009). The B73 maize genome: Complexity, diversity, and dynamics. Science, 326, 1112-1115.

Schoof, H., Lenhard, M., Haecker, A., Mayer, K. F., Jürgens, G., \& Laux, T. (2000). The stem cell population of Arabidopsis shoot meristems is maintained by a regulatory loop between the CLAVATA and WUSCHEL genes. Cell, 100, 635-644. 
Shi, J., Dong, J., Xue, J., Wang, H., Yang, Z., Jiao, Y., ... Huang, H. (2017). Model for the role of auxin polar transport in patterning of the leaf adaxial-abaxial axis. The Plant Journal, 92, 469-480.

Skirpan, A., Wu, X., \& McSteen, P. (2008). Genetic and physical interaction suggest that BARREN STALK1 is a target of BARREN INFLORESCENCE2 in maize inflorescence development. The Plant Journal, 55, 787-797.

Somssich, M., Je, B. I., Simon, R., \& Jackson, D. (2016). CLAVATA-WUSCHEL signaling in the shoot meristem. Development, 143, 3238-3248.

Tanaka, W., Pautler, M., Jackson, D., \& Hirano, H. Y. (2013). Grass meristems II: Inflorescence architecture, flower development and meristem fate. Plant and Cell Physiology, 54, 313-324.

Vollbrecht, E., \& Schmidt, R. J. (2009). Development of the inflorescences. Handbook of maize: Its biology (pp. 13-40). Springer, New York, NY.

\section{Copyrights}

Copyright for this article is retained by the author(s), with first publication rights granted to the journal.

This is an open-access article distributed under the terms and conditions of the Creative Commons Attribution license (http://creativecommons.org/licenses/by/4.0/). 